\title{
Fractionation and structural identification of antibiotic activity substances from Streptomyces herbaricolor HNS2-2
}

\author{
Lili Chen ${ }^{1,2}$, Youzhi Li ${ }^{1,3}$, Hongjian Zhu' ${ }^{1,3}$, Yuhua Liu ${ }^{1,3}$, Bida Gao ${ }^{1,3^{*}}$ \\ ${ }^{1}$ Hunan Agricultural University, Changsha, China \\ ${ }^{2}$ Hunan Provincial Center for Formented Food Engineering and Biotechnology, Changsha, China \\ ${ }^{3}$ Hunan Provicial University Key Lab for Plant Disease Control and Ulitization, Changsha, China; \\ *Corresponding Author: bdgao@yahoo.com.cn
}

Received 4 March 2012; revised 18 April 2012; accepted 12 May 2012

\begin{abstract}
Four groups of antibiotic activity compounds were separated and purified from the ethyl acetate fraction of a broth culture of Streptomyces herbaricolor HNS2-2. Trace analyses were performed and anti-microbial activities were determined. The antibiotic activity compounds were identified as quercetin dehydrate (1), p-hydroxyphenyl (2), 4'-hydroxyflavanone (3), and 3-hydroxyflavone (4) based on spectroscopic data. Compounds 1 - 4 showed significant antimicrobial activities against Staphylococcus aureus and the tobacco mosaic virus in vitro, suggesting their potential agricultural and medical applications.
\end{abstract}

Keywords: Streptomyces herbaricolor HNS2-2;

Quercetin Dehydrate; p-Hydroxyphenyl;

4-Hydroxyflavanone; 3-Hydroxyflavone; Bioactivity

\section{INTRODUCTION}

Filamentous actinomycetes, especially the members of the genus Streptomyces, are very important sources of different natural metabolites. These organisms possess a broad range of biological activities, such as antibiotic (e.g, streptomycin and oxytetracycline), antitumor (e.g., bleomycin and mitomycin), antifungal (e.g., nystatin and antimycin A), anti-tubercular (aprazamycin B and thiolactomycin), as well as pesticide (e.g., jinggangmycin and liuyangmycin) [1-3]. Streptomyces can also produce immunomodulators (e.g., tacrolimus and pimecrolimus), organic acids, amino acids, vitamins, steroids, and enzymes, as well as inhibit enzymatic activities [4,5]. Some can engage in different types of biological activities at the same time, or in special biological activities by metabolic regulation [6-8]. Previous studies on the biologi- cal activities of Streptomyces are diverse. However, they are still important potential resources for discovering novel biologically active sources.

In the present study, the ethyl acetate extract of the broth culture of Streptomyces herbaricolor HNS2-2 showed significant antimicrobial activity against Staphylococcus aureus and the tobacco mosaic virus (TMV) in vitro $[9,10]$. The isolation, purification, and structural identification of the antibiotic activity compounds in the extract were reported.

\section{MATERIAL AND METHODS}

\subsection{Microorganisms}

S. herbaricolor HNS2-2 was isolated in our laboratory from a soil sample obtained from the Shenlongjia Nature Reserve in Sichuan province, China. The strain was maintained in $40 \%$ glycerol microtubes at $-20^{\circ} \mathrm{C}$. The identity of $S$. herbaricolor was confirmed based on the morphology results of scanning electronic microscopy, culture characteristics, chemotaxonomic tests, and 16S rRNA analysis [9]. The other microorganisms used in the present study were $S$. aureus and TMV. S. aureus was maintained on nutrient agar slants at $4^{\circ} \mathrm{C}$, and a crude extract of TMV was prepared and stored in our laboratory.

\subsection{Culture Conditions for $S$. herbaricolor HNS2-2 and Preparation of Crude Antibiotic Activity Substances}

The culture medium for $S$. herbaricolor HNS2-2 was the same as that reported in literature [9]. First, the inoculum prepared by 6d-old $S$. herbaricolor HNS2-2 on a Gause No. 1 agar slant was inoculated in $300 \mathrm{~mL}$ Erlenmeyer flasks, which contained $30 \mathrm{~mL}$ of seed medium. The flasks were placed in a rotary shaker at $28^{\circ} \mathrm{C}$ and incubated at $180 \mathrm{rpm}$ for $18 \mathrm{~h}$. About $3 \mathrm{~mL}$ of seed-incubated liquid (inoculation number $=6 \%$ ) was trans- 
ferred into a $500 \mathrm{~mL}$ Erlenmeyer flask containing 100 $\mathrm{mL}$ of fermented liquid medium (medium volume $=$ $20 \%$ ). After $7 \mathrm{~d}$ of growth at $28^{\circ} \mathrm{C}$ on a rotary shaker at $220 \mathrm{rpm}$, the crude fermentation broth was acidized with $\mathrm{HCl}$ to $\mathrm{pH} 3.5$ at $55^{\circ} \mathrm{C}$ for $2 \mathrm{~h}$, and thoroughly filtered to separate the broth filtrate and mycelial cake. The broth supernatant was concentrated five times in an evapo-concentration decompressor at $55^{\circ} \mathrm{C}$. The extract containing crude antibiotic activity substances was obtained by extraction and evapo-concentration.

\subsection{Isolation of Antibiotic Activity Substances}

The antibiotic activity substance was isolated over a silica gel column (column $\Phi \times \mathrm{l}$ : $9 \mathrm{~cm} \times 80 \mathrm{~cm}$; silica gel 100 - 200 mesh) eluted with petroleum ether-ethyl acetate (20:1, 10:1, 5:1, 2:1, 1:1, and $0: 1 ; 500 \mathrm{~mL}$ each). There were 76 fractions obtained, and these fractions were combined into 12 fractions by a TLC plate using n-butyl alcohol-acetic acid-water (7:3:1.5) as developing solvents and collect similar components. Fractions 31 47 and $48-57$ were both antibiotic activity by trace analyses and determination with cup-plate method and inhibition zone determination.

Fraction 31 - 47 was placed in a silica gel column (column $\Phi \times 1$ : $2 \mathrm{~cm} \times 45 \mathrm{~cm}$; silica gel $200-300$ mesh) eluted with petroleum ether-ethyl acetate $(85: 15 ; 25 \mathrm{~mL}$ each) to afford pure compound 1 [fractions 37 - 41 and 23 - 26]. Fractions 37 - 41 and 79 - 86 were further separated in a silica gel column (column $\Phi \times 1$ : $2 \mathrm{~cm} \times 60 \mathrm{~cm}$; silica gel 200 - 300 mesh) eluted with petroleum etherethyl acetate (80:20; $20 \mathrm{~mL}$ each). TLC was performed on the eluent, and the products were collected to give pure compound 2 .

Fractions 48 - 57 were recrystallized in acetone and separated by Sephadex LH-20 eluted with acetone. The products were collected to obtain pure compound 3 .

The recrystallized residue was applied to a silica gel column (column $\Phi \times \mathrm{l}: 2 \mathrm{~cm} \times 50 \mathrm{~cm}$; silica gel $100-200$ mesh) using petroleum ether:ethyl acetate $(85: 15 ; 20 \mathrm{~mL}$ each) as the mobile phase. TLC was performed on fractions $(48$ - 57)-(3 - 6)-1-(4 - 7). The products were collected to obtained pure compound 4 .

The chemical structures of the pure compounds were confirmed via ${ }^{1} \mathrm{H}$ NMR and ${ }^{13} \mathrm{C}$ NMR. Tetramethylsilane (TMS) was used as the internal standard; $\mathrm{CDCl}_{3}$ and acetone-d6 were the solvents. The NMR spectra were compared with relevant references, and the identities of the compounds were further confirmed.

\subsection{Antimicrobial Activity Test}

The method of trace analyses and determination was that compounds from the isolation of antibiotic activity substances were tested for in vitro activity against $S$. aureus by the cup-plate method and inhibition zone determination, keep the positive compound, give up the negative compound, step by step. A $75 \%$ alcohol solution was used as a positive control, and aseptic normal saline was used as a negative control.

The antimicrobial activities of the pure compounds were determined as follows. The compounds were initially dissolved in acetone at a concentration of 1\% (diluted 100 times) and mixed with equal volumes of TMV crude extract for $30 \mathrm{~min}$. Stramonium was then introduced into the mixer via sap inoculation. The inhibiting effects of the compounds on Stramonium were recorded and compared. The compounds were also tested for in vitro activity against $S$. aureus by tube broth culture and spread plate colony calculation. Aseptic normal saline and acetone were used as negative controls.

\section{RESULTS}

\subsection{Fractionation and Structural Identification of Antibiotic Activity Substances}

Based on ${ }^{1} \mathrm{H}$ NMR and ${ }^{13} \mathrm{C}$ NMR data, the following structural information were obtained.

\subsubsection{Pure Compound 1}

Yellow powder, ${ }^{1} \mathrm{H}$ NMR $\left(500 \mathrm{MHz},\left(\mathrm{CD}_{3}\right)_{2} \mathrm{CO}\right): \delta_{\mathrm{H}}$ $6.27(1 \mathrm{H}, \mathrm{d}, J=1.4 \mathrm{~Hz}, 6-8), 6.52(1 \mathrm{H}, \mathrm{s}, \mathrm{H}-6), 6.99$ $(1 \mathrm{H}, \mathrm{d}, J=8.5 \mathrm{~Hz}, \mathrm{H}-5$ '), 7.70 (1 H, dd, $J=8.5 \mathrm{~Hz}, 2.2$ Hz, H-6'), 7.82 (1 H, d, $J=2.1 \mathrm{~Hz}, \mathrm{H}-2$ '), 12.18 (1 H, s, HO-3); ${ }^{13} \mathrm{C}$ NMR [125 MHz, $\left.\left(\mathrm{CD}_{3}\right)_{2} \mathrm{CO}\right]: \delta_{\mathrm{C}} 94.4(\mathrm{C}-8)$, 99.1 (C-6), 104.1 (C-10), 115.7 (C-2'), 116.2 (C-5'), 121.5 (C-6'), 123.7 (C-1'), 145.8 (C-4'), 147.0 (C-3'), 148.3 (C-2), 157.8(C-9), 162.3 (C-5), 165.0 (C-7), 176.5 (C-4).

The ${ }^{1} \mathrm{H}$ NMR and ${ }^{13} \mathrm{C}$ NMR data as well as the chemical structure were identical with those of quercetin dehydrate $[11,12]$. Hence, the pure compound was considered to be a monomer of quercetin dehydrate.

\subsubsection{Pure Compound 2}

White crystals, ${ }^{1} \mathrm{HNMR}\left(400 \mathrm{MHz},\left(\mathrm{CD}_{3}\right)_{2} \mathrm{CO}\right): \delta_{\mathrm{H}}$ 7.02 (2 H, d, $J=8.5 \mathrm{~Hz}, \mathrm{H}-2,6), 6.73(2 \mathrm{H}, \mathrm{d}, J=8.5 \mathrm{~Hz}$, H-3,5), 2.85(2 H, t, $J=7.6 \mathrm{~Hz}, \mathrm{H}-7$ ), 2.57 (2 H, t, $J=7.8$ $\mathrm{Hz}, \mathrm{H}-8),{ }^{13} \mathrm{C}$ NMR [100 MHz, $\left.\left(\mathrm{CD}_{3}\right)_{2} \mathrm{CO}\right]: \delta_{\mathrm{C}} 133.0$ (C-l), 130.2 (C-2,6), 116.2 (C-3,5), 156.7 (C-4), 37.3 (C-7), 31.3 (C-8), 177.0 (C-9).

The ${ }^{1} \mathrm{H}$ NMR and ${ }^{13} \mathrm{C}$ NMR data as well as the chemical structure of the compound were identical with those of p-hydroxyphenyl [13], the chemical structure of which is given in Figure 1(b).

\subsubsection{Pure Compound 3}

White powder, ${ }^{1} \mathrm{H}$ NMR $\left[500 \mathrm{MHz},\left(\mathrm{CD}_{3}\right)_{2} \mathrm{CO}\right]: \delta_{\mathrm{H}}$ 
2.76 (1 H, dd, $J=16.7 \mathrm{~Hz}, 2.8 \mathrm{~Hz}, 3-\mathrm{H}), 3.16$ (1 H, dd, $J$ = 16.7 Hz, 13.1 Hz, H-3), 5.50 (1 H, dd, $J=13.1 \mathrm{~Hz}, 2.7$ Hz, H-2), 6.90 (2 H, d, $J=8.5 \mathrm{~Hz}, \mathrm{H}-3$ ', H-5'), 7.03 7.08 (2 H, m, H-6, H-8), 7.43 (2 H, d, $J=8.5$ Hz, H-2', H-6’), 7.53 7.57 (1 H, m, H-7), 7.83 (1 H, dd, $J=7.8$ $\mathrm{Hz}, 1.6 \mathrm{~Hz}, \mathrm{H}-5), 8.51$ (1 H, s, $-\mathrm{OH}) ;{ }^{13} \mathrm{C} \mathrm{NMR}(125$ $\mathrm{MHz}, \mathrm{CDCl}_{3}$ ): $\delta_{\mathrm{c}} 45.8$ (C-3), 81.3 (C-2), 117.2 (C-3', 5'), 119.9 (C-8), 122.9 (C-10), 123.0 (C-6), 128.3 (C-5), 130.0 (C-2', 6'), 132.1 (C-l'), 137.7 (C-7), 159.6 (C-9), 163.6 (C-4'), 193.2 (C-4). The spectroscopic data and chemical structure of the compound were identical with those of 4-hydroxyflavanone [14], the chemical structure of which is given in Figure 1(c).

\subsubsection{Pure Compound 4}

Light-yellow powder, ${ }^{1} \mathrm{H}$ NMR (500 $\left.\mathrm{MHz}, \mathrm{CDCl}_{3}\right): \delta_{\mathrm{H}}$ 7.16 (1 H, s, OH), 7.40 7.43 (1 H, m, H-4'), 7.46 7.49 (1 H, m, H-8), 7.53 7.56 (2 H, t, $J=7.2$ Hz, H-3', H-5'), 7.58 (1 H, d, $J=8.4 \mathrm{~Hz}, \mathrm{H}-6), 7.69 \sim 7.72$ (1 H, m, $\mathrm{H}-7$ ), $8.25 \sim 8.28$ (3 H, m, H-2', H-6', H-5); ${ }^{13} \mathrm{C}$ NMR (125 MHz, $\mathrm{CDCl}_{3}$ ): $\delta \mathrm{c} 118.3$ (C-8), 120.6 (C-10), 124.5
(C-6), 125.4 (C-4’), 127.7 (C-2', 6'), 128.6 (C-3’, 5’), 130.2 (C-5), 131.0 (C-l'), 133.6 (C-7), 138.5 (C-3), 144.9 (C-9), 155.4 (C-2), 173.5 (C-4). Based on the spectroscopic data, the compound was identified $[15,16]$ as $3-$ hydroxyflavone.

\subsection{Antimicrobial Activity of the Pure Compounds against $S$. aureus and TMV}

Table 1 shows that the inhibition of pure compound 1 was stronger than those of the other pure compounds, the inhibition rate of lesion wan $89.12 \%$. Nevertheless, pure compound 2 exhibited destructive effects on Stramonium, resulting in death.

Figure 2 shows that the compounds exhibited anti- $S$. aureus activity. The number of $S$. aureus in a petri dish was obviously lower in the test group (left) than the control group(upper right was aseptic normal saline negative controls and lower right was acetone negative controls). The number of $S$. aureus in a petri dish from pure compound 1 to 4 were $(12.5 \pm 0.50) \mathrm{CFU} /$ petri dish, (3.00 \pm<smiles>O=c1c(O)c(-c2ccc(O)c(O)c2)oc2cc(O)cc(O)c12</smiles>

(a)<smiles>O=C(O)CCc1ccc(O)cc1</smiles>

(b)<smiles>O=C1CC(c2ccc(O)cc2)Oc2ccccc21</smiles>

(c)<smiles>O=c1c(O)c(-c2ccccc2)oc2ccccc12</smiles>

(d)

Figure 1. Chemical structures of the pure compounds. (a): Pure compound 1,quercetin dehydrate; (b): Pure compound 2,p-hydroxyphenyl; (c): Pure compound 3,4'-hydroxyflavanone; (d): Pure compound 4, 3-hydroxyflavone.

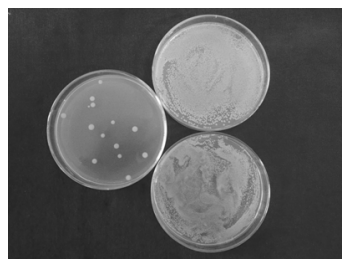

(a)

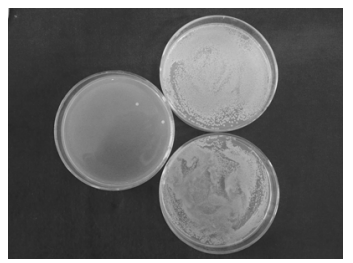

(b)

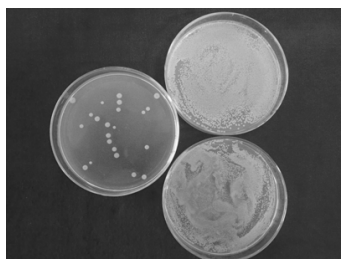

(c)

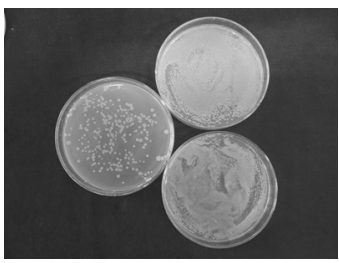

(d)

Figure 2. Antimicrobial activity of the pure compoundsagainst $S$. aureus. (a) Pure compound 1 and control group; (b) Pure compound 2 and control group; (c) Pure compound 3and control group; (d) Pure compound 4 and control group.

Table 1. Antimicrobial activity of the pure compounds against TMV.

\begin{tabular}{|c|c|c|}
\hline Pure compound & Lesion number & Inhibition rate (\%) \\
\hline 1 & 37 & $89.12 \pm 0.44 \mathrm{a}^{* *}$ \\
\hline 2 & * & * \\
\hline 3 & 155 & $53.03 \pm 0.67 c^{* *}$ \\
\hline 4 & 161 & $51.20 \pm 0.40 \mathrm{~d}^{* *}$ \\
\hline control group & 329 & \\
\hline
\end{tabular}

*The Stramonium died after sap inoculation; ${ }^{* *}$ Different letters showed significant difference at 0.05 level. 
0.34) CFU/petri dish, (24.50 $\pm 0.0 .98)$ CFU/petri dish and (235.00 \pm 1.27$) \mathrm{CFU} /$ petri dish respectively. Pure compound 2 exhibited the strongest such activity. The antimicrobial activities of pure compounds 1,3 , and 4 are also shown.

\section{DISCUSSION}

The current study showed that $S$. herbaricolor could produce the flavonoids quercetin dehydrate, p-hydroxyphenyl, 4'-hydroxyflavanone, and 3-hydroxyflavone, and the compounds have significant bioactivities. These report has never been previously described.

More than 4000 varieties of flavonoids have been identified in nature, especially in plants (e.g., fruit, vegetables, grains, bark, roots, stems, flowers, tea, and wine) [17]. Flavonoids have a wide range of functions. They play important roles as signal molecules for the induction of nod genes [18-20], serve as precursors for the production of major phytoalexins during plant-microbe interactions [21,22], and inhibit pathogen attack [23,24]. However, flavonoids, being naturally produced by plants, are very complex. Some are also produced in very low quantities that cannot meet human requirements. Obtaining sufficient amounts of natural flavonoids will lead to the depletion of natural resources.

Actinomyces species have the advantages of rapid growth, precisely controllable growth condition, relatively easy to be genetically manipulated, abundant supply of substrates, and applicable in the mature liquid submerged fermentation technique, etc. Flavonoid production in the microorganism starter $S$. herbaricolor is feasible and can overcome the above mentioned problems. Further research on the determination, anabolism, and fermentation of $S$. herbaricolor antibiotic activity flavonoids will benefit their industry-scale production and application.

\section{ACKNOWLEDGEMENTS}

This work was financially supported by the National Natural Science Foundation of China (No. 30771437), the Natural Science Foundation of Hunan Science and Technology Committee (No. 08JJ6017). Professor Bida Gao is project leader.

\section{REFERENCES}

[1] Chen, L.L. and Lu, Y.X. (2005) Screening of high yielding jinggangmycin strain by microwave mutation. Biotechnology, 13, 14-15.

[2] Hesketh, A.R., Chandra, G., Shaw, A.D., Rowland, J.J., Kell, D.B., Bibb, M.J. and Chater, K.F. (2002) Primary and secondary metabolism, and post-translational protein modifications, as portrayed by proteomic analysis of Streptomyces coelicolor. Molecular Microbiology, 46, 917-932. doi:10.1046/j.1365-2958.2002.03219.x
[3] Mellouli, L., Karray-Rebai, I., Sioud, S., Ameur-Mehdi, R.B. and Naili, B. (2004) Efficient transformation procedure of a newly isolated Streptomyces sp. TN58 strain producing antibacterial activities. Current Microbiology, 49, 400-406. doi:10.1007/s00284-004-4292-9

[4] Ramírez-Suero, M., Khanshour, A., Martinez, Y. and Rickauer, M. (2010) A study on the susceptibility of the model legume plant Medicago truncatula to the soilborne pathogen Fusarium oxysporum. European Journal of Plant Pathology, 126, 517-530. doi:10.1007/s10658-009-9560-X

[5] Ni, X.P., Li D., Yang, L.H., Huang, T.J., Li, H. and Xia, H.Z. (2011) Constructionof kanamycin B overproducing strain by genetic engineering of Streptomyces tenebrarius. Applied Microbiology and Biotechnology, 89, 723-731. doi:10.1007/s00253-010-2908-5

[6] Kavitha, A. and Vijayalakshmi, M. (2011) Partial purification and antifungal profile of chitinase produced by Streptomyces tendae TK-VL_333. Annals of Microbiology, 61, 597-603. doi:10.1007/s13213-010-0178-1

[7] Tian, X.W., Long, J.Y., Bai, H.J. and Wu, W.J. (2004) Studies on the fungicidal activity of secondary metabolic products of actinomycetes. Plant Protection, 30, 51-54.

[8] Ershov, Y.V. (2007) 2-C-methylerythritol phosphate pathway of isoprenoid biosynthesis as a target in identifying new antibiotics, herbicides, and immunomodulators: A review. Applied Biochemistry and Microbiology, 43, 115138. doi:10.1134/S0003683807020019

[9] Chen, L.L, Gao, B.D and Yi, T.Y. (2008) Antiviral Activity and identification of Streptomyces strain HNS2-2. Chinese Journal of Biological Control, 24, 69-74.

[10] Chen, L.L., Gao, B.D., Liu X.Y. and Chen, D.C. (2009) Preliminary study on physical chemical character of Streptomycete HNS2-2 antimicrobial activity. Biotechnology, 19, 29-32.

[11] Satterfield, M. and Brodbelt, J.S. (2001) Structural characterization of flavonoid glycosides by collisionally activated dissociation of metal complexes. Journal of the American Society for Mass Spectrometry, 12, 537-549. doi:10.1016/S1044-0305(01)00236-7

[12] Mikstacka, R., Rimando, A.M. and Ignatowicz, E. (2010) Antioxidant effect of trans-resveratrol, pterostilbene, quercetin and their combinations in human erythrocytes in vitro. Plant Foods for Human Nutrition, 65, 57-63. doi:10.1007/s11130-010-0154-8

[13] Fedorova, T.E., Ivanova, S.Z. and Babkin, V.A. (2010) Spiroflavonoid compounds: Structure and distribution in nature review. Russian Journal of Bioorganic Chemistry, 36, 793-801. doi:10.1134/S1068162010070022

[14] Calderone, V., Chericoni, S., Martinelli, C., Testai, L. and Nardi, A. (2004) Vasorelaxing effects of flavonoids: Investigation on the possible involvement of potassium channels. Naunyn-Schmiedeberg's Archives of Pharmacology, 370, 290-298. doi:10.1007/s00210-004-0964-z

[15] Tyukavkina, N.A., Pogodaeva, N.N., Brodskaya, E.I. and Sapozhnikov, Y.M. (1975) Ultraviolet absorption of flavonoids. V. The structure of 3- and 5-hydroxyflavones. Chemistry of Natural Compounds, 11, 613-616. 


\section{doi:10.1007/BF00567696}

[16] Maciejewicz, W. and Soczewinski, E. (2000) Chemometric characterization of TLC systems of the type silica-binary non-aqueous mobile phase in the analysis of flavonoids. Chromatographia, 51, 473-477. doi:10.1007/BF02490487

[17] Kim, B.-G., Sung, S.H., Chong, Y., Lim, Y. and Ahn, J.-H. (2010) Plant flavonoid $O$-methyltransferases: Substrate specificity and application. Journal of Plant Biology, 53, 321-329. doi:10.1007/s12374-010-9126-7

[18] Ferrer, J.L., Austin, M.B., Stewart, C.J. and Noel, J.P. (2008) Structure and function of enzymes involved in the biosynthesis of phenylpropanoids. Plant Physiology and Biochemistry, 46, 356-370. doi:10.1016/j.plaphy.2007.12.009

[19] Nissler, L., Gebhardt, R. and Berger, S. (2004) Flavonoid binding to a multi-drug resistance transporter protein: An STD-NMR study. Analytical and Bioanalytical Chemistry, 379, 1045-1049. doi:10.1007/s00216-004-2701-3

[20] Novák, K., Lisá, L. and Skrdleta, V. (2004) Rhizobial nod gene-inducing activity in pea nodulation mutants, dissociation of nodulation and flavonoid response. Physiologia Plantarum, 120, 546-555. doi:10.1111/j.0031-9317.2004.0278.x

[21] Lozovaya, V.V., Lygin, A.V., Zernova, O.V., Ulanov, A.V.,
Li, S., Hartman, G.L. and Widholm J.M. (2007) Modification of phenolic metabolism in soybean hairy roots through down regulation of chalcone synthase or isoflavone synthase. Planta, 225, 665-679. doi:10.1007/s00425-006-0368-z

[22] Shimada, N., Sato, S., Akashi, T., Nakamura, Y., Tabata, S., Ayabe, S. and Aoki, T. (2007) Genome-wide analyses of the structural gene families involved in the legumespecific 5-deoxyisoflavonoid biosynthesis of Lotus japonicus. DNA Research, 14, 25-36. doi:10.1093/dnares/dsm004

[23] Naoumkina, M., Farag, M.A., Sumner, L.W., Tang, Y., Liu, C.J. and Dixon, R.A. ( 2007) Inaugural article, different mechanisms for phytoalexin induction by pathogen and wound signals in Medicago truncatula. Proceedings of the National Academy of Sciences of the United States of America, 104, 17909-17915. doi:10.1073/pnas.0708697104

[24] Bajpai, V.K., Yoon, J.I. and Kang, S.C. (2009) Antifungal potential of essential oil and various organic extracts of Nandina domestica Thunb. against skin infectious fungal pathogens. Applied Microbiology and Biotechnology, 83, 1127-1133. doi:10.1007/s00253-009-2017-5 